\title{
A method and application of multi-scale validation in spatial land use models
}

\author{
Kasper Kok $^{\mathrm{a}, *}$, Andrew Farrow ${ }^{\mathrm{b}}$, A. Veldkamp ${ }^{\mathrm{a}}$, Peter H. Verburg ${ }^{\mathrm{a}}$ \\ ${ }^{a}$ Laboratory of Soil Science and Geology, Wageningen University, PO Box 37, \\ 6700 AA, Wageningen, The Netherlands \\ b Departamiento de GIS, Centro Internacional de Agricultura Tropical (CIAT), AA 6713, Cali, Colombia
}

\begin{abstract}
The majority of the large number of existing land use models lack a proper validation, often because of data problems. Moreover, despite recognition of the necessity to incorporate a multi-scale analysis, scale dependencies are normally not considered during validation. In this paper, a multi-scale land use change modelling framework, conversion of land use and its effects (CLUE), is calibrated for Costa Rica and validated at five spatial resolutions for Honduras and Costa Rica. Both countries experienced locally very strong actual land use changes. Calibration runs show that the model is very sensitive to changes in the autonomous development parameter, which defines the influence of the finest resolution. Validation results are very satisfactory for both countries. Especially, changes in major land use types are reproduced with the model. Changes in localised land use types are more difficult to project. The magnitude of gains and magnitude of losses are slightly underestimated in all cases. The multi-scale validation demonstrates that results improve strongly, and exponentially, with decreasing spatial resolution. Strong reduction of the number of observations results in a correlation between actual and modelled changes that approximates the perfect value of 1 . The study demonstrates that the CLUE modelling framework can reproduce changes as they took place in Central America in the 1970s and 1980s, and shows how conclusions can differ depending on the scale at which validation is performed. (C) 2001 Elsevier Science B.V. All rights reserved.
\end{abstract}

Keywords: Model; Validation; Land use; Central America; Scale; GIS; Spatially explicit

\section{Introduction}

\subsection{Land use models and validation}

Use of models in land use research is almost universal (Beck, 1999). Extensive overviews are given by Kaimowitz and Angelsen (1998) and Lambin (1994), while both studies consider only deforestation. The number of spatially explicit land use models is much smaller (Sklar and Costanza, 1991), but rapidly

\footnotetext{
* Corresponding author. Tel.: +31-433882664; fax: +31-433884916.

E-mail address: k.kok@icis.unimaas.nl (K. Kok).
}

increasing. In spite of the large number of models and in spite of a general agreement that validation should be an essential part of any model (Borenstein, 1998), the majority lack a validity check. An analysis of error propagation and parameter sensitivity is usually conducted, but for various reasons a full-fledged model validation is hindered in most spatially explicit land use models. Particularly models that operate on a higher scale lack an independent second data set (e.g., Leemans and van den Born, 1994; Heuvelink and Pebesma, 1999), and because of the large extent, controlled experiments cannot be run. Besides, many models seek to explore future scenarios of land use change, and are therefore impossible to validate 
completely. A proper validation not only requires a second independent data set, it should be preceded by model calibration, which calls for an additional data set.

\subsection{Scale issues}

Besides practical difficulties to validate land use models, there is another complicating factor, which is referred to as the scale problem, or the fact that processes and relationships change both with the (spatial and temporal) resolution and extent at which they are observed. The problem was first recognised by ecologists (O'Neill, 1988; Meentemeyer, 1989), and recent awareness is growing in a number of other disciplines (Becker et al., 1999; Wagenet, 1998; Jansen and Stoorvogel, 1998). With one notable exception (Costanza, 1989), this growing interest in multi-scale analysis is not accompanied by special interest in multi-scale model validation, even though most modellers do not claim that their models are valid at the scale of analysis (Jansen, 1998). There is no reason to assume that the scale effect is less influential in model validation and the results of a multi-scale model could therefore potentially be misused if not coupled with a multi-scale validation. This paper offers a first step towards such a validation by a systematic study of the effects of spatial resolution with a constant extent on the validity of model results.

\subsection{The CLUE modelling framework}

The CLUE modelling framework, which is validated in this study, is one of the few spatially explicit land use models that analyses land use change at multiple scales. CLUE was developed and tested at country level for Costa Rica (Veldkamp and Fresco, 1996a,b; Schoorl et al., 1997). Since, the model has been successfully run for various countries in Latin America and Asia: Java (Verburg et al., 1999a); China (Verburg et al., 1999b); Atlantic zone of Costa Rica (Kok and Veldkamp, 2000); Ecuador (De Koning et al., 1999). It uses a (statistical) description of land use patterns and their dependency on a set of socio-economic and biophysical variables at a number of spatial resolutions. The temporal dynamics of land use are analysed in a separate module, which is based on changes in demand for agricultural commodities at the highest level of aggregation (usually a country). The multi-scale descriptions of the spatial patterns at one point in time are subsequently combined with temporal changes at the national level in the CLUE allocation module. In this way, the spatial effects of different possible future pathways of land use change can be evaluated. A three step top-down procedure with bottom-up feedback is followed, where aggregated total demand is allocated at two different spatially explicit levels. Total demand is first allocated at an intermediate scale; in a second step allocation of the 'regional' demand of the intermediate level is further refined at a basic grid level. For details on the CLUE allocation module we refer to an article by Verburg et al. (1999c).

Recently, CLUE has been applied to Central America (see Farrow and Winograd, 2001; Kok and Veldkamp, 2001). CLUE-CA incorporates the six most important land use types in terms of area and economic revenue: annual crops (mainly maize (Zea mays), beans (Phaseolus spp.), rice (Oryza sativa), and sorghum (Sorghum spp.)); bananas (Musa spp.); coffee (Coffea spp.); sugar cane (Saccharum officinarum, representing the permanent crops); pasture; and natural vegetation. Scenarios are developed that explore a number of different possible future pathways of land use changes between 1996 and 2010. Scenarios include a natural hazard, a sustainable future, and various future pathways of economic growth. The finest resolution is a grid cell of $15 \times 15 \mathrm{~km}^{2}$, which is not treated as a homogeneous unit. More than one land use type is usually present within a cell. CLUE-CA includes two spatial resolutions, and special emphasis is put on the effects of a varying spatial extent. The temporal resolution is 1-year, with a time span of 15 years.

\subsection{Objectives}

The main objective is to analyse the performance of CLUE-CA, using two independent data sets for both Costa Rica and Honduras. In order to achieve this, the model is calibrated for Costa Rica at the finest resolution and a sensitivity analysis of key parameters is performed. Subsequently the model is validated at four coarser resolutions for Costa Rica and at five resolutions for Honduras. The validation concerns changes in the past and the quantity of change was therefore known. Validation was consequently 
restricted to the location of change and assumed correct total quantities. As it is the first time the model is used to project land use changes at supra-national level, particular interest is given to the question how the CLUE allocation procedure copes with dynamics of several countries at the same time. An analysis of the temporal dynamics is made to gain understanding of the temporal realisation of spatial land use change patterns. Finally, a comparison with the statistical input of CLUE-CA is included to relate the performance of the model to the quality of that input.

\subsection{Actual land use changes}

In both Costa Rica and Honduras, agricultural expansion at the expense of natural vegetation (forest) was the main process in the 1970s and 1980s. Land use dynamics were steered by strong and sometimes rapid changes that took place at local, national, and regional scales. At the regional level, civil wars and the second oil crisis in 1979 and its aftermath strongly influenced development of land use in Central America (Diaz-Bonilla, 1990; Brockett, 1988). Of all Central American countries, Honduras had the lowest per capita income, the highest population growth rate, and largest influence from the US market, whereas Costa Rica was, and continues to be, the richest country with the lowest population growth rates (World Bank, 1998). These national differences were reflected in the rates of land use change. At the local level, most conspicuous changes were related to large-scale land redistribution programs formulated to deal with increasing poverty in the 1970s (CCE, 1990). The result was a massive migration of rural population, especially in Costa Rica, where the programs were more successful (Jones, 1988). Fig. 1 shows the yearly population growth rates between 1973 and 1984 for Costa Rica and 1974 and 1993 for Honduras and the distribution of natural vegetation in 1973 (Costa Rica) and 1974 (Honduras). Note the negative population growth in parts of both countries, and the high positive correlation between population growth and presence of natural vegetation. The observed (dis-)similarities offer a good opportunity to test the robustness of the CLUE allocation module.

Land use changes of the six land use types included in CLUE-CA are given in Table 1. Relative annual changes varied between $-0.2 \%$ for natural vegetation in both countries and $+2.8 \%$ per year for sugar cane in Costa Rica and were of similar magnitude for both countries. This annual deforestation rate of $0.2 \%$ was very low compared to a rate of at least $2 \%$ generally reported in literature (Stonich, 1993; Becker, 1998). The rates calculated here are net rates of changes and include development of secondary vegetation and other types of regrowth, whereas reported rates normally indicate gross deforestation of primary forest. Absolute changes were normally larger for Honduras as the country is twice the size of Costa Rica and the period of change was as twice as long.
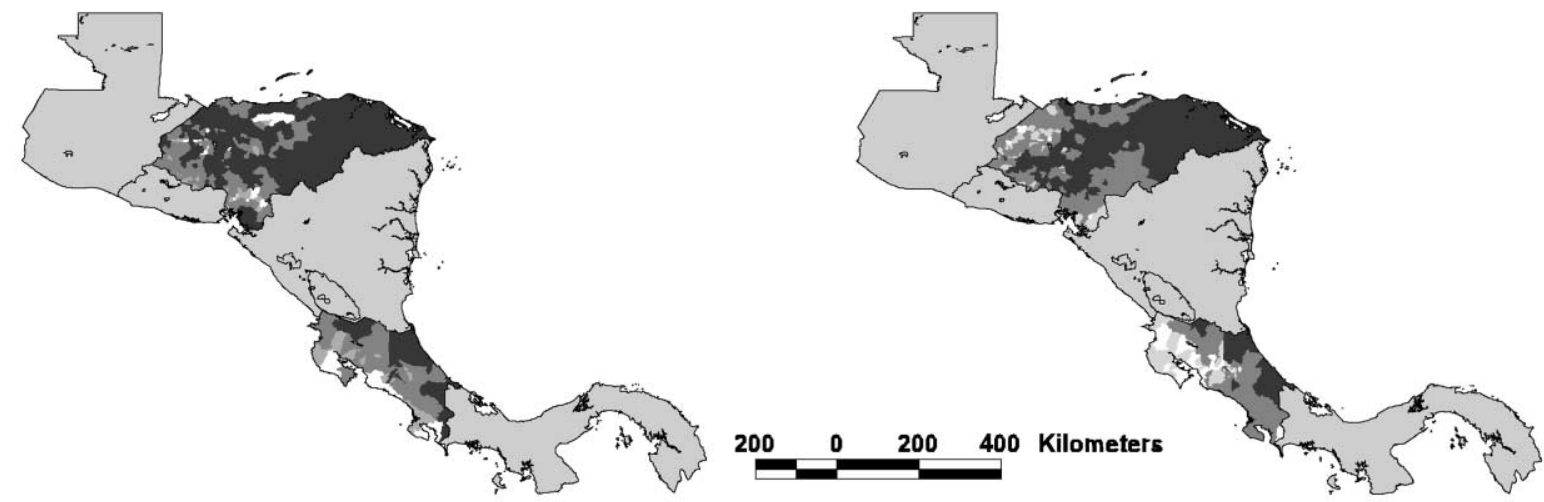

Fig. 1. Left side: Distribution of natural vegetation in Costa Rica (1973) and Honduras (1974). White: 0-20\%; light grey: 20-40\%; medium grey: 40-60\%; dark grey: $>60 \%$ cover percentage. Right side: Yearly total population growth rates for Honduras (average between 1974 and 1993) and Costa Rica (1973-1984). White: population decrease ( $<0 \%$ growth); light grey: stable population $(0-0.5 \%)$; medium grey: slight population increase $(0.5-2 \%)$; dark grey: strong population increase $(>2 \%)$. 
Table 1

Approximate area and area changes for six land use types in Costa Rica and Honduras between 1973 and 1984 , and 1974 and 1993, respectively

\begin{tabular}{|c|c|c|c|c|c|c|c|}
\hline Country & Variable & Annuals & Bananas & Coffee & Sugar cane & Pasture & Natural vegetation \\
\hline \multirow[t]{5}{*}{ Costa Rica } & Area $1973\left(\mathrm{~km}^{2}\right)$ & 2700 & 350 & 790 & 330 & 14500 & 29900 \\
\hline & Area $1984\left(\mathrm{~km}^{2}\right)$ & 3500 & 300 & 850 & 450 & 14200 & 29300 \\
\hline & Total change $\left(\mathrm{km}^{2}\right)$ & 800 & -50 & 60 & 120 & -300 & -600 \\
\hline & Total change $(\%)$ & 30 & -11 & 8 & 40 & -2 & -2 \\
\hline & Annual change $(\%)$ & 2.4 & -1.0 & 0.7 & 2.8 & -0.2 & -0.2 \\
\hline \multirow[t]{5}{*}{ Honduras } & Area $1974\left(\mathrm{~km}^{2}\right)$ & 4500 & 240 & 1000 & 250 & 12000 & 79300 \\
\hline & Area $1993\left(\mathrm{~km}^{2}\right)$ & 5500 & 300 & 1500 & 330 & 13500 & 76000 \\
\hline & Total change $\left(\mathrm{km}^{2}\right)$ & 1000 & 60 & 500 & 80 & 1500 & -3300 \\
\hline & Total change $(\%)$ & 23 & 28 & 56 & 35 & 13 & -4 \\
\hline & Annual change $(\%)$ & 1.1 & 1.2 & 2.4 & 1.6 & 0.6 & -0.2 \\
\hline
\end{tabular}

\section{Methods and material}

\subsection{Data}

Validation of CLUE-CA is restricted to Honduras and Costa Rica, being the countries for which two independent, high-quality data sets of land use are available. Land use data are derived from agricultural censuses, which contain detailed information on land use distribution at the crop level. In Costa Rica agricultural censuses were conducted in 1973 and 1984 (DGEC, 1976, 1987) and contain information for more than 400 districts; Honduran agricultural censuses are available for 1974 and 1993 (DGEC, 1978; SECPLAN, 1994) and include close to 300 administrative units.

Within the range of scales considered here, population density continues to be one of the key driving forces of land use change in Latin America (Rudel and Roper, 1997; De Koning et al., 1998). Given the population migration within the countries, spatially explicit information of at least two dates is necessary to calibrate and validate the model. For Costa Rica as well as Honduras, population censuses were conducted close to the years of the agricultural censuses.

\subsection{Model calibration and sensitivity analysis}

In this paper, sensitivity analysis refers to parameters within the CLUE allocation procedure. Parameters in the demand module that regulate the total quantity of change, like GDP per capita or consumption per capita, are not included. For model calibration the data sets of Costa Rica are used, as lack of a third data set for either Costa Rica or Honduras prevents the execution of an independent calibration. Because processes in Costa Rica and Honduras were largely similar over the time period that was considered and rates of changes were in the same order of magnitude, calibration for Costa Rica with subsequent validation for Honduras is justified. The validation for Costa Rica has to be evaluated carefully, since the basic grid level was used to calibrate the model.

Within the CLUE allocation module, there are two key input parameters, which need to be calibrated: SCALE_FACT and AUTODEV.

1. Scale parameter, SCALE_FACT. Determines to what extent the elasticity changes as calculated at the coarse resolution will influence elasticity for changes at the fine resolution. This is its most important use:

$$
\begin{aligned}
\text { REL_CHANGE }_{t}= & \left(\frac{\text { REL_CHANGE }_{t-1}}{\text { SCALE_FACT }_{1}}\right)+1 \\
& -\left(\frac{1}{\text { SCALE_FACT }_{1}}\right) \\
\text { ELAS1 }=\text { ELAS0 } & \times \text { REL_CHANGE }_{t}
\end{aligned}
$$

where REL_CHANGE is the cell specific relative change in area for each land use type (unitless), ELAS1 the cell and land use specific elasticity to changes at fine resolution (fraction of total change), ELAS0 the land use specific elasticity to changes 
at coarse resolution (fraction of total change), $t$ the year index.

SCALE_FACT changes the value of REL CHANGE, which in turn influences the elasticity to change at the fine resolution. The higher SCALE_FACT, the closer REL_CHANGE will be 1 , the more elastic changes at the fine resolution will be, and less the influence of the coarse resolution. At higher values of SCALE_FACT than approximately 10 , the influence of the coarse resolution on the final output at the fine resolution becomes negligible.

2. Autonomous development parameter, AUTODEV. Determines the relative importance of national quantity of change and changes at the finest resolution. This is one of the key uses:

$$
\begin{aligned}
\operatorname{ACTCOV}_{t}= & \mathrm{ACTCOV}_{t-1} \\
& +\left(\operatorname{REGCOV}_{t}-\mathrm{ACTCOV}_{t-1}\right) \\
& \times \mathrm{AUTODEV}
\end{aligned}
$$

where $\mathrm{ACTCOV}_{t}$ is the actual cell and land use specific area (ha/grid), REGCOV $_{t}$ the cell and land use specific area as calculated by statistical analyses (ha/grid), $t$ the year index.

The unitless AUTODEV (value between 0 and 1) determines to what extent cell specific changes will be governed by local preferences (REGCOV-ACTCOV) instead of by national changes. The higher the value of AUTODEV, the stronger the local effect. At values above 0.50 , the effect of further augmentation of AUTODEV becomes very small. At a value of 1 , all changes are autonomous and the influence of national demand is negligible.

Model sensitivity for changes in the two key parameters mentioned is assessed by repeating model runs, varying the values of SCALE_FACT or of AUTODEV. Used values include $0.05,0.10,0.25$, and 0.50 for AUTODEV and 1, 2, 5, and 10 for SCALE_FACT. The range of values is based on results of previous model calibrations for Ecuador and China. After preliminary analysis of the results, a value of 2 for SCALE_FACT and of 0.25 for AUTODEV were adopted to validate the model. The influence of the coarser resolution is thus somewhat reduced and the influence of local preferences as compared to the national trend is substantially increased. A summary of the charac-
Table 2

Range of values of SCALE_FACT and AUTODEV, two key parameters in CLUE allocation module

\begin{tabular}{lcc}
\hline Parameter & SCALE_FACT & AUTODEV \\
\hline Minimum & 1 & 0 \\
Fine resolution dominates & $<2$ & $>0.20$ \\
Coarse resolution dominates & $>5$ & $<0.05$ \\
Maximum & $\infty$ & 1 \\
Adopted value after calibration & 2 & 0.25
\end{tabular}

teristics of SCALE_FACT and AUTODEV is given in Table 2 .

\subsection{Multi-scale validation}

In this paper, validation includes only the projection of the location of change. The quantity of change is set to be correct at the country level. For both countries the same validation procedure is followed. Within the framework of CLUE-CA, a set of multiple regression equations was previously created, that describe the relationship between patterns of land use and a set of explanatory variables at two different resolutions $\left(15 \times 15 \mathrm{~km}^{2}\right.$ and $\left.75 \times 75 \mathrm{~km}^{2}\right)$ for the oldest of the two data sets available. A complete description of the methods and results of the statistical analysis is given by Kok and Veldkamp (2001). Using this set of equations, the CLUE allocation module is run, starting at the oldest year until the most recent year. Results are annual maps of land use between 1973 and 1984 for Costa Rica, and between 1974 and 1993 for Honduras. Validation is quantified by comparing the modelled and actual land use changes between calibration date and validation date, as opposed to comparing resulting maps of 1984 and 1993 without accounting specifically for the change that occurred. Thus, the validation becomes independent from the total quantity of change at national level between start and end date and from the time span.

Besides the basic grid resolution $\left(15 \times 15 \mathrm{~km}^{2}\right)$, four additional coarser resolutions for validation are created (see Table 3). To facilitate interpretation of results for potential stakeholders, resolutions are based on existing administrative divisions rather than artificial scales that could be created by averaging grid cells into larger grids. Three resolutions are created by grouping cells of the basic grid according 
Table 3

Basic information of five resolutions used for multi-scale validation and entire country. Number of observations and average unit size $\left(\mathrm{km}^{2}\right)$ are given for Honduras (HON) and Costa Rica (COS)

\begin{tabular}{|c|c|c|c|c|c|}
\hline \multirow[t]{2}{*}{ Resolution (HON and COS) } & \multicolumn{2}{|c|}{ Number of observations } & \multicolumn{2}{|c|}{ Average size of unit $\left(\mathrm{km}^{2}\right)$} & \multirow{2}{*}{$\begin{array}{l}\text { Comments } \\
(\mathrm{HON} \text { and COS) }\end{array}$} \\
\hline & $\mathrm{HON}$ & $\mathrm{COS}$ & $\mathrm{HON}$ & $\operatorname{COS}$ & \\
\hline Basic grid & 431 & 216 & 225 & 225 & $15 \times 15 \mathrm{~km}^{2}$, level of analysis \\
\hline District & 118 & 50 & 822 & 972 & Lowest administrative level \\
\hline Canton & 72 & 31 & 1347 & 1568 & Intermediate administrative level \\
\hline Province & 17 & 7 & 5704 & 6943 & Highest sub-national administrative level \\
\hline Agroecological zones & 3 & 3 & 32325 & 16200 & Low and dry; low and wet; high \\
\hline Country & 1 & 1 & 96975 & 48600 & Total area is based on gridded data \\
\hline
\end{tabular}

to different administrative levels (districts, cantons, and provinces). The number of administrative units defined the number of observations. A fourth, most coarse, level is created by grouping cells to three agroecological zones: (1) altitude $<500 \mathrm{~m}$ and at least two consecutive dry months; (2) altitude $<500 \mathrm{~m}$ and no consecutive dry months; (3) altitude $\geq 500 \mathrm{~m}$. A visual representation of the various resolutions in Honduras is given in Fig. 2.

In order to quantify relationships between actual and modelled land use changes, the correlation coefficient $(r)$ and the slope of the best linear relationship $\left(\beta_{\mathrm{b}}\right)$ are calculated, using the ordinary least squares method, at every resolution and for every land use type. Additional analyses include a $t$-test on the significance of the intercept and a $t$-test on whether $\beta_{\mathrm{b}}$ is significantly different from 1 . The adopted manner to quantify validation results is, strictly spoken, a misuse of the regression tool (Mitchell, 1997), and could pose interpretational problems. For example, results from testing the null hypothesis that the slope of the line does not differ significantly from 1 are difficult to interpret unambiguously, and the modelled and actual values cannot be treated as dependent and independent sets. We therefore utilise it mostly as a relative measure, to detect differences among spatial resolutions.

\subsection{Temporal dynamics}

The CLUE allocation module produces yearly land use maps. To analyse land use dynamics through time for the 11-year validation run for Costa Rica and the 20-year run for Honduras, cell specific changes during every 2 -year period are calculated, by averaging year to year changes that proved relatively unstable. Land use specific changes are classified into three classes:

\section{Basic grid}



Province

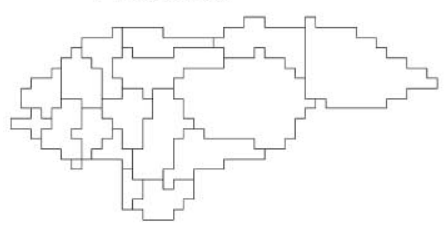

District

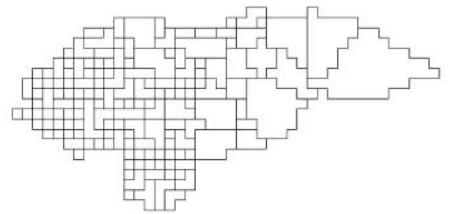

Agroecological zones

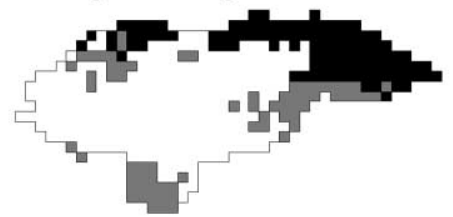

Canton
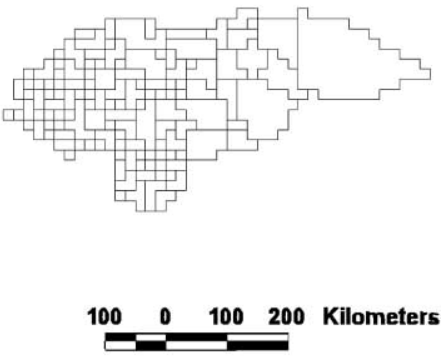

Fig. 2. Five resolutions used for validation of Honduran data 
cells with a decreasing land use percentage, cells with an increasing land use percentage, and cells where land use did not change substantially over any period of 2 years. Besides, for the decreasing and increasing class the average magnitude of change is calculated. By grouping cells in three classes, the spatial component is largely lost, but temporal detail is maintained. Only the basic grid resolution is analysed.

\subsection{Comparison with statistical analysis}

An important input of the CLUE allocation module is a set of multiple regression equations that describe land use patterns in a given year. For CLUE-CA, multiple regression analyses were performed at two resolutions. The finest resolution equalled the basic grid of this paper $\left(15 \times 15 \mathrm{~km}^{2}\right)$, a second resolution was created by aggregating 25 cells $\left(75 \times 75 \mathrm{~km}^{2}\right)$. From the results, the so-called regression covers can be calculated. Subsequently, the correlation coefficients between the actual land use distribution in a given year and the 'prediction' by the statistical model for that same year can be calculated. Those correlation coefficients can be compared to the correlation coefficients of the validation described above. The former $r$ 's represent the quality of the equations that are the core input of the allocation procedure. The latter are the results of the validation and represent the quality of the output of the CLUE model. Thus we can evaluate to what extent the success of allocation depends on the goodness-of-fit of the input equations.

\section{Results}

\subsection{Model sensitivity}

The model is not very sensitive for changes in SCALEFACT, which regulates the influence of the coarse resolution on the fine resolution. The correlation coefficients $(r$ 's) and slope of the regression line $\left(\beta_{\mathrm{b}}\right.$ 's) between actual and modelled changes in area, obtained using higher (5 or 10) or lower (1) values for SCALE_FACT, do not differ greatly from the results obtained in the validation run with a SCALE_FACT of 2. At higher values, the model performance is slightly different in the sense that hot-spots of change are more clustered, due to the larger influence of the coarse resolution.

The model proves very sensitive to changes in the value of AUTODEV, which regulates the influence of national changes on the fine resolution. In Fig. 3, $r$ 's and $\beta_{\mathrm{b}}$ 's of the relationship between actual and modelled changes in pasture area are given at different values of AUTODEV. Correlation coefficients gradually increase up to a value of 0.25 for AUTODEV, after which $r$ stabilises. At all values of AUTODEV, the $r$ is reasonably high. The reaction of the $\beta_{\mathrm{b}}$ 's on a

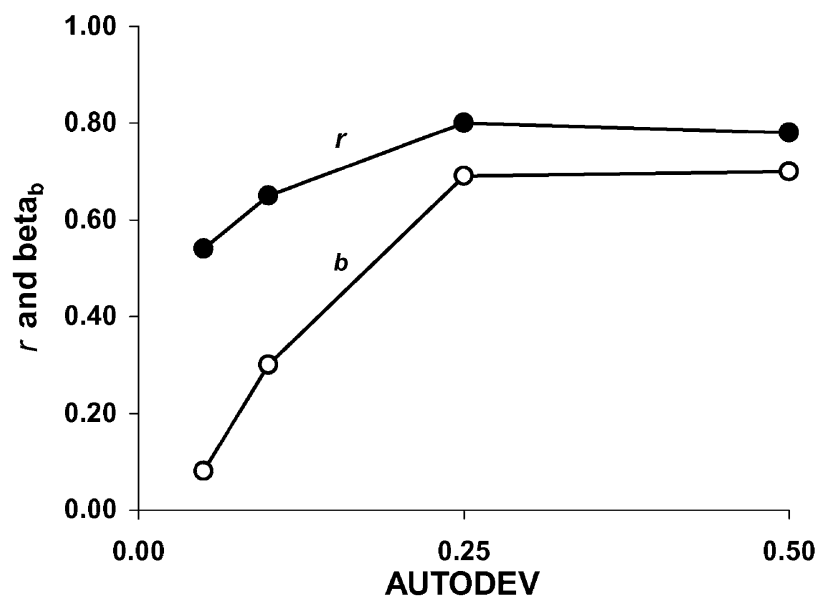

Fig. 3. Sensitivity of correlation coefficients $(r, P<0.01)$ and slope of the best linear relationship $\left(\beta_{\mathrm{b}}\right)$ between modelled and actual changes in pasture area in Costa Rica at the basic grid to changes in the value of AUTODEV. 
changing AUTODEV is very strong. Augmentation of the value of AUTODEV from 0.05 to 0.25 results in an immediate and substantial improvement of the $\beta_{\mathrm{b}}$ 's. Further increase to 0.50 has no effect on the model results. The low $\beta_{\mathrm{b}}$ 's indicate that there is an underestimation of both the strong decreases in pasture in the southwest and increases in the northeast of Costa Rica. At low values of AUTODEV, the model cannot simulate the strong local changes that took place. The allocation module is apparently very sensitive for changes of AUTODEV between 0.05 and 0.25 .

\subsection{Validation}

The results for Costa Rica at the basic grid are included, although this data set is used to calibrate the model and can strictly speaking not to be used for validation purposes.
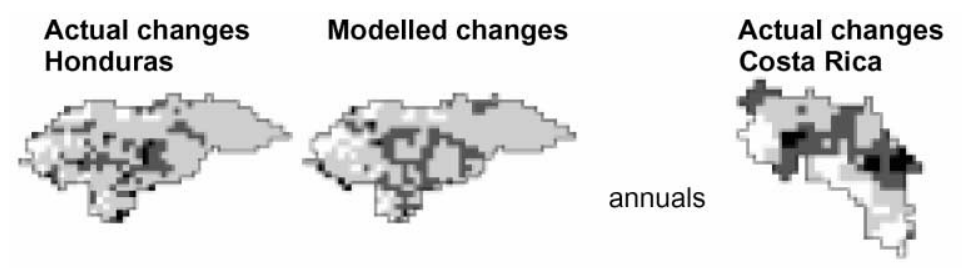

\section{Modelled changes}
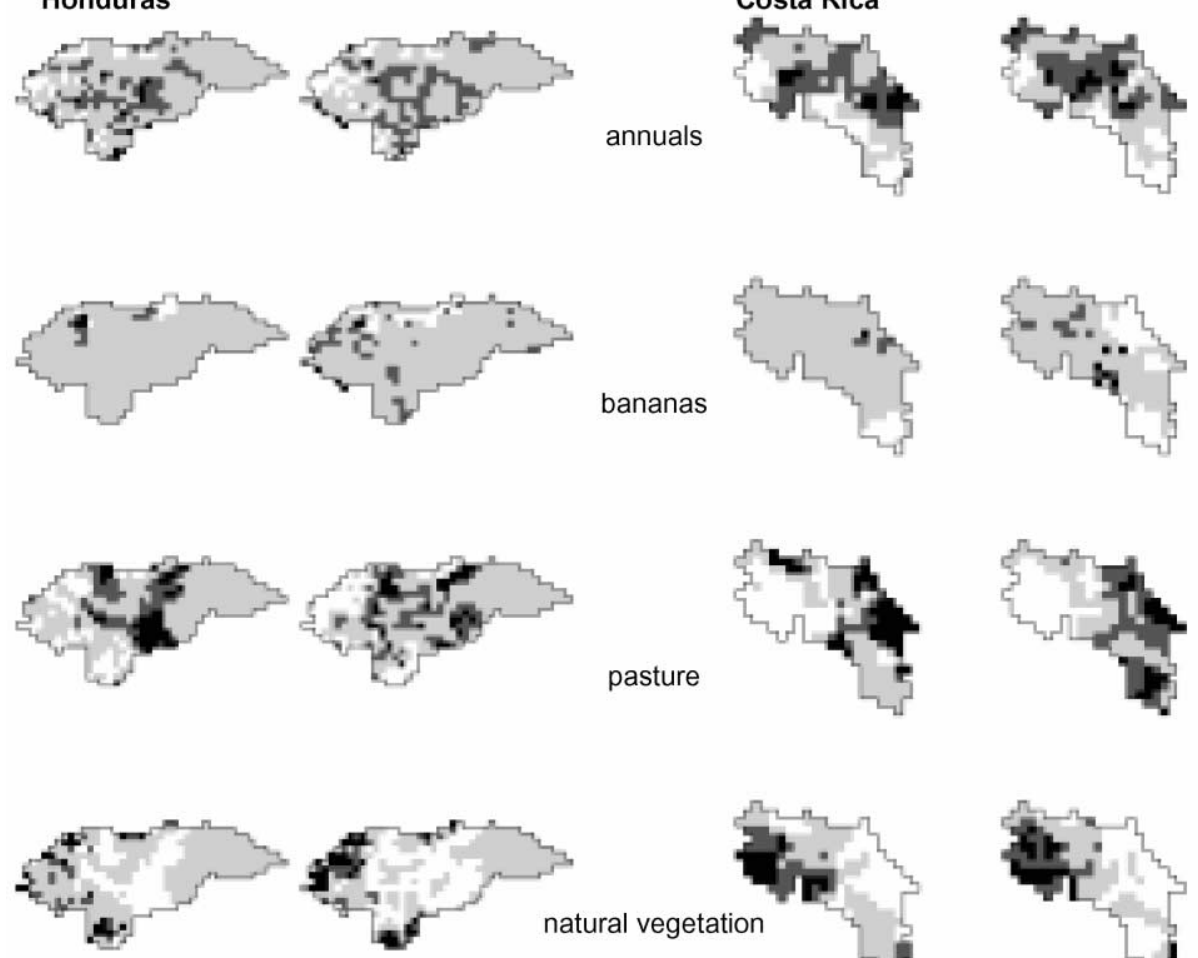

natural vegetation
3.2.1. Qualitative comparison: hot-spots of change

In Fig. 4, maps are presented that depict hot-spots of satisfactory way. Especially for pasture and natural vegetation, modelled and actual hot-spots of change coincide. Both the gradual deforestation in large areas in Honduras, and the reforestation in the southwestern part coupled with a rapid deforestation in the East and the presence of high-quality soils are among the sation of large-scale migration programs in the east and to a much lesser extent in the south that occurred 
Table 4

Significant correlation coefficients $(P<0.01)$ of relation between actual and modelled land use distribution for six land use types and five resolutions for Costa Rica and Honduras. The average value did not include bananas and sugar cane

\begin{tabular}{|c|c|c|c|c|c|c|}
\hline \multirow[t]{2}{*}{ Country } & \multirow[t]{2}{*}{ Land use type } & \multicolumn{5}{|c|}{ Data resolution } \\
\hline & & Basic grid & District & Canton & Province & $\mathrm{AEZ}^{\mathrm{a}}$ \\
\hline \multirow[t]{7}{*}{ Costa Rica } & Annuals & 0.72 & 0.71 & 0.73 & 0.80 & 0.90 \\
\hline & Bananas & 0.15 & n.s. ${ }^{b}$ & n.s. & n.s. & 0.97 \\
\hline & Coffee & 0.86 & 0.73 & 0.77 & 0.89 & 0.97 \\
\hline & Sugar cane & n.s. & n.s. & n.s. & n.s. & -0.97 \\
\hline & Pasture & 0.80 & 0.80 & 0.78 & 0.92 & 0.99 \\
\hline & Natural vegetation & 0.81 & 0.81 & 0.76 & 0.93 & 1.00 \\
\hline & Average & 0.80 & 0.76 & 0.76 & 0.89 & 0.97 \\
\hline \multirow[t]{7}{*}{ Honduras } & Annuals & 0.69 & 0.72 & 0.74 & 0.80 & 1.00 \\
\hline & Bananas & n.s. & 0.35 & n.s. & n.s. & 0.87 \\
\hline & Coffee & n.s. & n.s. & n.s. & n.s. & 0.91 \\
\hline & Sugar cane & n.s. & n.s. & n.s. & n.s. & n.s. \\
\hline & Pasture & 0.57 & 0.59 & 0.60 & 0.73 & 1.00 \\
\hline & Natural vegetation & 0.59 & 0.62 & 0.64 & 0.73 & 1.00 \\
\hline & Average & 0.62 & 0.64 & 0.66 & 0.75 & 1.00 \\
\hline
\end{tabular}

${ }^{\text {a }}$ Agroecological zone.

${ }^{\mathrm{b}}$ Not significant.

in reality (Brockett, 1988), but was not included as a potential driving force during the statistical analysis, could explain the mismatch. The locations of change in area of annuals are reasonably well modelled, although the exact location of hot-spots in Honduras not always matches. The model performance considering bananas is less satisfying. Areas of decrease generally coincide, but hot-spots of increase in banana area are not always in the correct places. The model is unable to project the highly clustered distribution of new banana plantations. The same conclusion can be drawn concerning the likewise clustered distributed coffee and sugar cane plantations (not shown).

\subsubsection{Quantitative comparison}

In the majority of the cases, the intercept of the linear relationship does not differ significantly from 0 . The analysis of the effect of setting the intercept to 0 is therefore small and is not treated separately. The remainder of the quantitative comparison focuses on the correlation coefficients and slope of the regression line.

3.2.2.1. Correlation coefficients. All correlation coefficients $(r)$ between modelled and actual land use distribution are given in Table 4. In Fig. 5, the rela- tionships between actual and modelled changes in the area of pasture are visualised for five resolutions. The statistical significance generally decreases at the two coarsest resolutions although the $r$ further increases, which is due to the low number of observations.

Important observations are:

- For most land use types, $r$-values are high (Table 4). At the basic grid level, the average $r$ for the largest four land use types is 0.80 for Costa Rica and 0.62 for Honduras. A consistent and highly significant relation between actual and modelled changes exists at all levels of resolution.

- The model performance is better for Costa Rica than for Honduras. Especially changes in areas of natural vegetation (0.81 versus 0.59 at the basic grid level), pasture (0.80 versus 0.57$)$ and coffee plantations (no significant correlation in Honduras) are better modelled. From Fig. 5 it can be concluded that for pasture neither high correlations nor differences between both countries are caused by outliners or lack of normal distribution. Graphs for natural vegetation and annuals support the conclusion. The fact that the allocation module is calibrated using the Costa Rican data set is a probable cause of the better model performance. 

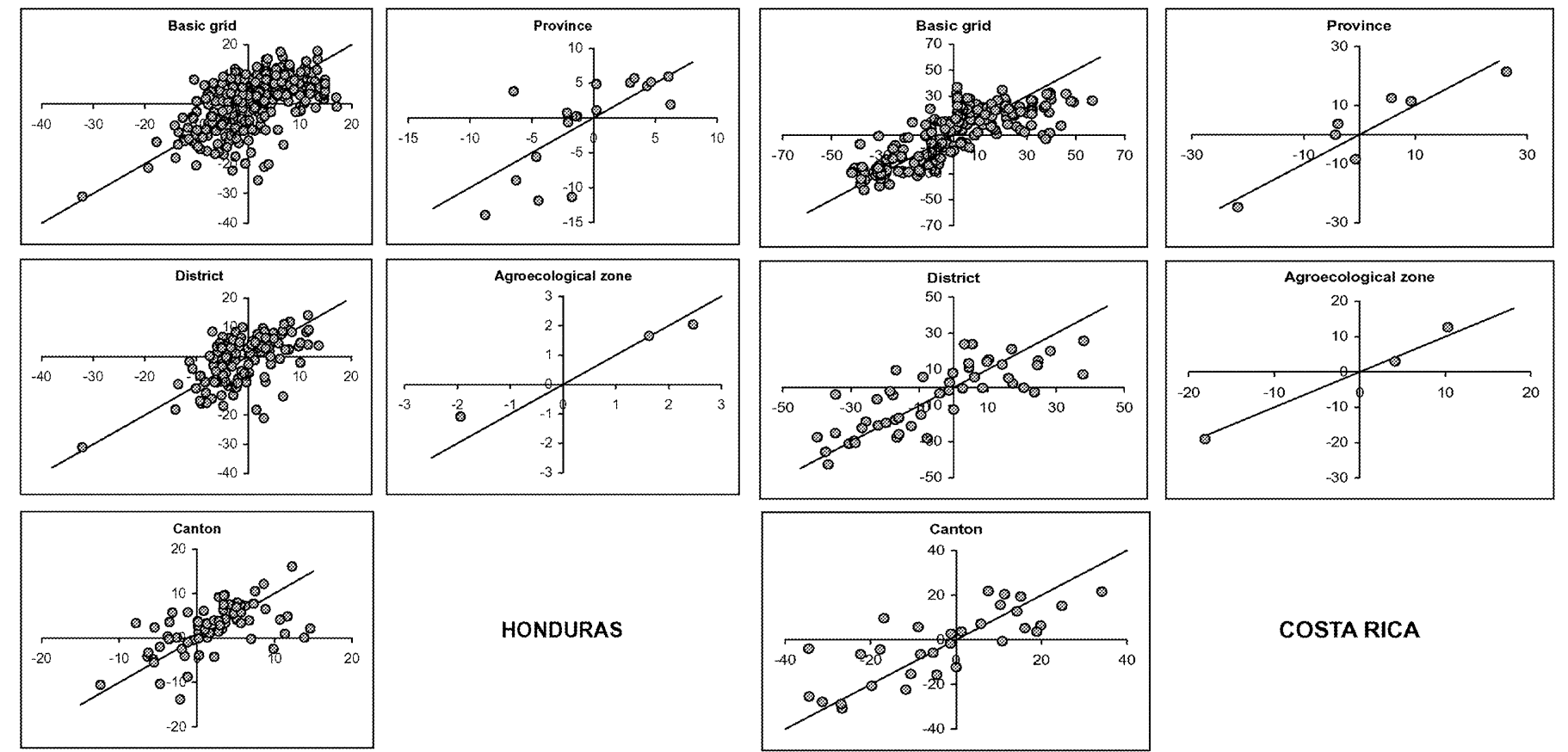

COSTA RICA

HONDURAS

Fig. 5. Relation between actual ( $X$-axis) and modelled ( $Y$-axis) changes in pasture area (ha) for five resolutions. Lines indicate the hypothetical 1:1 relationship. 
Table 5

Slopes of regression lines significantly different from zero $(P<0.01)$ of relation between actual and modelled land use distribution for six land use types and five resolutions for Costa Rica and Honduras. $t$-tests were not performed at AEZ level

\begin{tabular}{lllllll}
\hline Country & Land use type & \multicolumn{2}{l}{ Data resolution } & & & \\
\cline { 3 - 7 } & & Basic grid & District & Canton & Province & AEZ \\
\hline Costa Rica & Annuals & $0.51^{\mathrm{b}}$ & $0.55^{\mathrm{b}}$ & $0.54^{\mathrm{b}}$ & $0.63^{\mathrm{b}}$ & 0.71 \\
& Bananas & $0.32^{\mathrm{b}}$ & n.s. $^{\mathrm{c}}$ & n.s. & n.s. & 0.64 \\
& Coffee & $0.81^{\mathrm{b}}$ & $0.67^{\mathrm{b}}$ & $0.67^{\mathrm{b}}$ & $0.64^{\mathrm{b}}$ & 0.73 \\
& Sugar cane & n.s. & n.s. & n.s. & n.s. & 0.81 \\
& Pasture & $0.64^{\mathrm{b}}$ & $0.67^{\mathrm{b}}$ & 0.67 & 0.96 & 0.99 \\
& Natural vegetation & $0.72^{\mathrm{b}}$ & $0.65^{\mathrm{b}}$ & 0.64 & 0.87 & 0.91 \\
& Annuals & $0.70^{\mathrm{b}}$ & $0.71^{\mathrm{b}}$ & 0.70 & 1.03 & 1.04 \\
& Bananas & n.s. & $0.55^{\mathrm{b}}$ & n.s. & n.s. & 0.72 \\
& Coffee & n.s. & n.s. & n.s. & n.s. & 0.55 \\
& Sugar cane & n.s. & n.s. & n.s. & n.s. & n.s. \\
& Pasture & $0.66^{\mathrm{b}}$ & 0.73 & 0.56 & 0.08 & 1.10 \\
& Natural vegetation & $0.68^{\mathrm{b}}$ & 0.80 & 0.59 & 0.99 & 1.05 \\
\hline
\end{tabular}

${ }^{\text {a }}$ Agroecological zone.

b Significantly lower than 1 .

${ }^{\mathrm{c}}$ Not significantly different from 0 .

- The correlation between actual and modelled changes almost invariably increases with spatial resolution, which can be partly attributed to the loss of variance at coarser resolutions.

- The relation between loss of resolution and gain of model performance is exponential rather than linear. Reducing resolution from the basic grid to the canton level, thus reducing the number of observations to roughly $20 \%$, has no beneficial effects on the $r$. A substantial gain in explanatory power is obtained when aggregating to the province level or AEZ level. All relationships approach the perfect fit at the agroecological zone level $(r=1.0$ in Table 4), which is partly caused by the fact that national quantities are set to be correct.

- The performance of the model when addressing the permanent crops is poor. Often the $r$ is not significant, and even negative values (sugar cane in Costa Rica) occur. Changes in banana and coffee area, on the other hand, can be successfully modelled when aggregated to AEZ level.

3.2.2.2. Regression coefficients. The slope of the best possible linear relation $\left(\beta_{\mathrm{b}}\right)$ of the majority of the regressions differs significantly from $0(P<0.01)$. Results are given in Table 5. The minimum value for the individual models is 0.32 (bananas at basic grid in Costa Rica); the maximum value is 1.10 (pasture at AEZ level in Honduras). The test whether the $\beta_{\mathrm{b}}$ differed from the ideal value of 1 , however, results in many significantly lower values. In Fig. 6, the development of $\beta_{\mathrm{b}}$ is depicted for averages of the most important land use types. It shows the clearly exponential improvement of the $\beta_{\mathrm{b}}$ 's.

The model systematically, and over all scales, underestimates sometimes locally severe land use

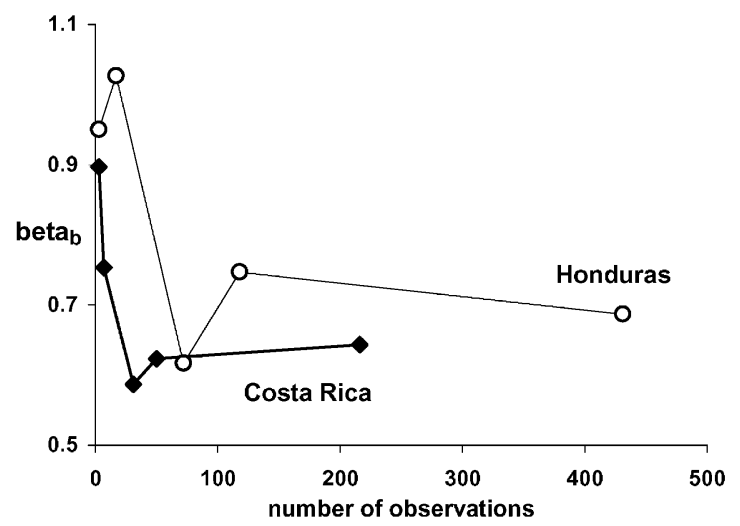

Fig. 6. Slope of the best possible linear relationship between actual and modelled changes at five resolutions $\left(\beta_{\mathrm{b}}\right)$, indicated by the number of observations, for Costa Rica and Honduras. Values are averages for annuals, pasture, natural vegetation and coffee. 
Pasture, Costa Rica



Wincrease decrease Dstable

Bananas, Honduras

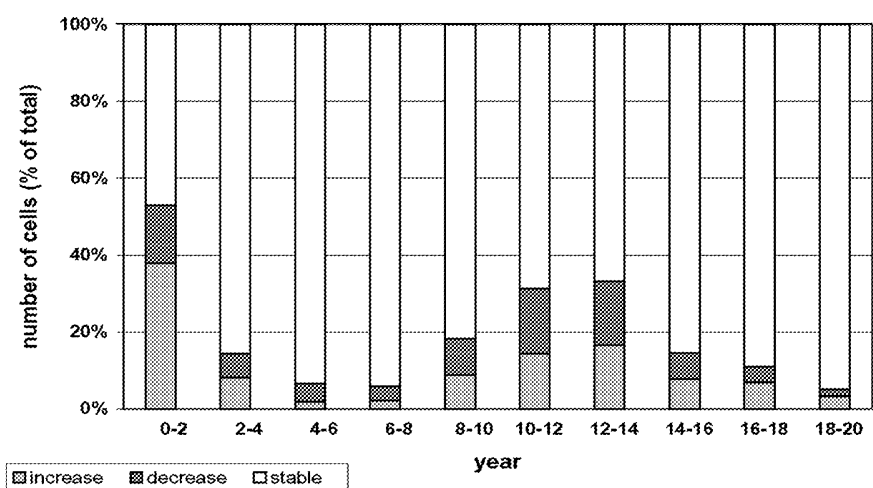

Pasture, Costa Rica

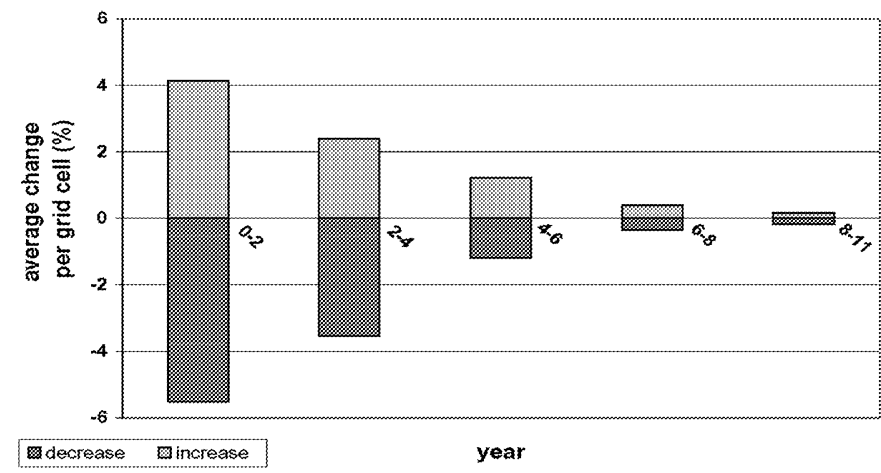

Bananas, Honduras

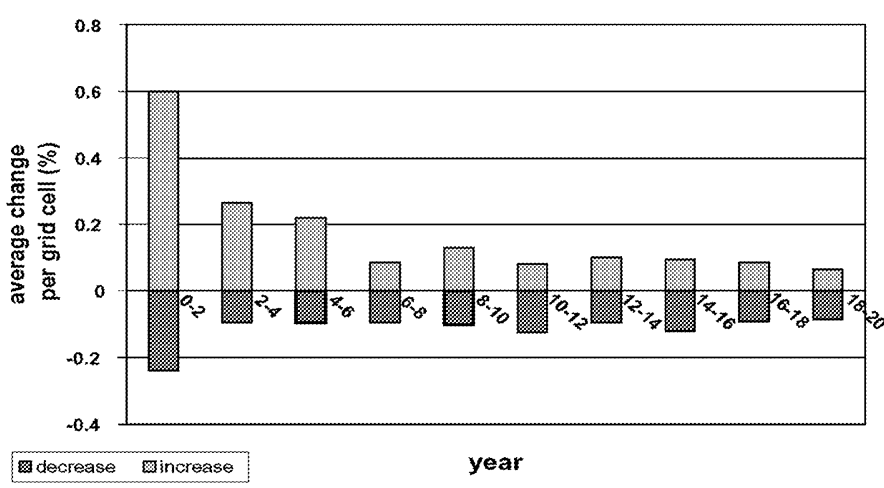

Fig. 7. Temporal characteristics of changes in pasture area in Costa Rica (top) and bananas in Honduras (bottom). On the left-hand side, the percentage cells that is classified stable, increasing or decreasing over time is depicted. On the right-hand side, the average change in area (\% of a cell) for cells classified as decreasing or increasing is given. Every column represents the average dynamics of a 2-year period. 
changes as they occurred, particularly in Costa Rica. Nevertheless, model performance again improves when resolution is reduced. Similar to the changes in $r$, the improvement becomes substantial at the coarsest resolutions and is mostly exponential.

\subsection{Temporal dynamics}

In Fig. 7, temporal changes of two typical cases are presented; pasture in Costa Rica and bananas in Honduras. Depicted are the percentage of cells that decrease or increase (stable when change $<0.10 \%$ ), and the average change of those groups of cells. Temporal changes within a cell are highly non-linear. Pasture in Costa Rica represents a typical example of the functioning of the three large land use types: annuals, pasture, and natural vegetation. In the first couple of years, annual changes are highly dynamic (top left, Fig. 7). About $50 \%$ of the cells show a decreasing cover, the other $50 \%$ increase, and the average change (Fig. 7, top right) is almost 5\% per cell per year. After about 6-8 years, the number of cells that stabilise their cover increases rapidly and the average change reduces sharply. During the last years, stability is reached in more than $75 \%$ of the cells, and the average change is smaller than $0.5 \% \mathrm{yr}^{-1}$. Bananas in Honduras represent a typical case of the three minor land use types in terms of area, and display a different pattern of change. Both the percentage of cells that change (about 50\%) and the magnitude of change (less than $0.5 \% \mathrm{yr}^{-1}$ ) are far below the numbers for the large land use types. Given the large number of cells without banana cover and small total area coverage, this is to be expected. Again, changes in the first years are highly dynamic, but unlike the large land use types, an initial diminishing change is followed by a second period of enhanced dynamics. Usually dynamics again decrease towards the final year of the simulation.

\subsection{Comparison with input data}

The results for the multiple regression analyses of 1993 for Honduras and 1984 for Costa Rica are given in Table 6. From the statistical analysis it was concluded that neither the explaining factors nor the goodness-of-fit change significantly over time (Kok and Veldkamp, 2001). The validation results are therefore compared with the most recent and complete data set available and not with the input data of the model. The values in Table 6 can be compared with the $r$ 's in Table 4. The data at the basic grid $\left(15 \times 15 \mathrm{~km}^{2}\right)$ can be compared directly; the coarser scale of Table 6 $\left(75 \times 75 \mathrm{~km}^{2}\right)$ is best compared with the validation results at the province level, which has approximately the same number of observations.

Results vary between land use type, country, and resolution. The overall model performance for Costa Rica is better than could be expected based on the statistical relations. For Honduras, where the statistical relations are very strong, the opposite holds. At the coarser resolution, the $r$ 's of the statistical models are invariably higher. When examining individual land use types, the same division into two groups surfaces. The distribution of permanent crops, which gives the poorest results in the validation, also gives the lowest values of $r$ of the statistical models. The difference

Table 6

Correlation coefficients between land use distribution as calculated by multiple regression techniques and actual land use area for six land use types at two spatial resolutions

\begin{tabular}{|c|c|c|c|c|}
\hline \multirow[t]{2}{*}{ Land use type } & \multicolumn{2}{|c|}{ Costa Rica (1984) } & \multicolumn{2}{|c|}{ Honduras (1993) } \\
\hline & $15 \times 15 \mathrm{~km}^{2}$ & $75 \times 75 \mathrm{~km}^{2}$ & $15 \times 15 \mathrm{~km}^{2}$ & $75 \times 75 \mathrm{~km}^{2}$ \\
\hline Number of observations & 216 & 10 & 431 & 22 \\
\hline Annuals & 0.58 & 0.80 & 0.89 & 0.98 \\
\hline Bananas & 0.72 & 0.77 & 0.71 & 0.95 \\
\hline Coffee & 0.88 & 0.94 & 0.63 & 0.92 \\
\hline Sugar cane & 0.53 & 0.62 & 0.51 & 0.80 \\
\hline Pasture & 0.51 & 0.79 & 0.78 & 0.96 \\
\hline Natural vegetation & 0.60 & 0.90 & 0.87 & 0.99 \\
\hline Average $^{a}$ & 0.64 & 0.86 & 0.79 & 0.96 \\
\hline
\end{tabular}

${ }^{a}$ Includes natural vegetation, pasture, annuals, and coffee. 
between large covering land uses and permanent crops is far less in the statistical relations than after the model runs. It is thus possible to explain reasonably well the static distribution of permanent crops, but it is difficult to subsequently use these relationships to model changes over time. For large covering land uses, CLUE-CA in some cases performs better than was expected based on the multiple regression analyses. Especially the allocation of pasture and natural vegetation in Costa Rica during validation runs is more successful than the pattern description $(0.60$ and 0.51 as compared to 0.80 and 0.81 for natural vegetation and pasture at the basic grid, respectively).

\section{Discussion}

The sensitivity analysis includes two key parameters of the CLUE allocation procedure, that both regulate the influence of the coarse resolution on the fine resolution in the CLUE allocation module. The model proves to be especially sensitive to changes in AUTODEV, the parameter that controls the influence of autonomous development at grid cell level as compared to national demand changes. Model performance for Costa Rica increases when using relatively high values of AUTODEV, leading to a large influence of local dynamics. This finding is in accordance with the highly dynamic local changes as they took place in Costa Rica in the 1970s and 1980s. With a single model parameter, slow and steady changes governed by national demand fluctuations, as well as dynamic local changes are simulated.

The most important changes in land use are captured for both Honduras and Costa Rica, two countries in which similar processes but with a different intensity took place. The overall model performance is slightly better for Costa Rica, for which the model is calibrated. Particularly good results are obtained for annuals, pasture and natural vegetation. It is especially noteworthy that CLUE is able to reproduce the large-scale forest regrowth in the southwestern part of Costa Rica, although the net process between 1973 and 1984 was one of deforestation. It proves that the CLUE modelling framework successfully synthesises interacting local and regional processes.

The scale of validation strongly influences the conclusions that can be drawn. Correlation coefficients and regression coefficients change exponentially with spatial resolution. When reducing resolution, the regression line rapidly approaches the 1:1 line and the correlation coefficient approaches 1 . For both countries, the model performance is nearly perfect when results are aggregated to the level of agroecological zones. The underestimation of the $\beta_{\mathrm{b}}$ 's indicates that the CLUE allocation module tends to smooth the results too much, but the rapid increase at high aggregation levels strongly suggests that modelled changes are in the vicinity of actual changes. Additional proof is found in the visual comparison (Fig. 4), where e.g. the allocation of annuals is modelled in generally the correct area. To combine resolution and validity in an optimal way, it seems best to perform validation at least at two scales: the scale of analysis (high resolution) and a very high aggregation level (high validity).

The validation described in this paper concerns only land use patterns and does not include an analysis on varying quantities at national level. Because those quantities are assumed correct, regression lines will by definition be perfect at the national level. The fact that lines approach the 1:1 line at the AEZ level can partly be attributed to the fact that quantities are fixed. The exponential rather than linear curve when scaling up cannot be explained by this 'cheating on quantities'.

Changes in land use types that are omnipresent or that do not change abruptly are reproduced successfully. Much less satisfying results are obtained for permanent crops, that are cultivated on highly clustered, large plantations. An exception is the cultivation of coffee in Costa Rica, which is controlled by smallholders in small corporations, and which is reflected in better validation results (Table 4). The apparent problem with smaller land use types can be partly explained by examining the temporal dynamics. The competitive power of large land use types is relatively high (see Fig. 7). The initially high dynamics indicate that unfavourable conditions are abandoned and favourable cells occupied. After the new situation is established, those large covering land use types do not further change their distribution. The second peak in the temporal dynamics of the smaller land use types can be explained by assuming that those land use types have greater difficulties to occupy favourable locations. The manner in which competition is incorporated in CLUE might overrate the competitive power of the large land 
use types. The spatially explicit addition of economic variables, like price of labour, or location of processing plants, could account for the economic strength of bananas, coffee, and to a lesser extent of sugar cane. This conclusion is confirmed by the analysis of differences between the statistical analysis (Table 6) and validation results (Table 4 ) that shows that correlation coefficients of at least 0.50 for permanent crops in multiple regression equations often do not result in a significant models during validation.

CLUE was validated for three additional cases at various scales: the island Java (basic grid: $20 \times 20 \mathrm{~km}^{2}$; Verburg et al., 1999a), the country Ecuador $\left(10 \times 10 \mathrm{~km}^{2}\right.$; De Koning et al., 1998) and the Atlantic Zone of Costa Rica $\left(2 \times 2 \mathrm{~km}^{2}\right.$; Kok and Veldkamp, 2000). However, those studies did not separate calibration and validation, nor did they include a systematic evaluation of the multi-scale validation results. Moreover, except for the Java case none were based on two equally detailed independent data sets. Nevertheless, findings serve to confirm the results of this paper. De Koning et al. (1998) presented r's between 0.66 and 0.92 for changes in the area of annuals, pasture and permanent crops for the canton $(n=162)$ and province $(n=19)$ aggregation levels, with a significant increase from canton to province level. The high values for the lumped class of permanent crops $(>0.65)$ indicate that grouping of bananas, coffee, and sugar cane can improve the results of this study. Verburg et al. (1999a) aggregated their validation for Java to three levels, obtaining stable figures from the basic grid level ( $n=329, r$ between 0.20 and 0.60 ) to a coarser scale ( $n=97, r$ between 0.22 and 0.66 ) and a dramatic increase going to agroecological zones ( $n=4, r=0.93)$. Model validation for the Atlantic Zone of Costa Rica (Kok and Veldkamp, 2000) yielded similar successes for pasture and forest $(r=0.90)$, but faced similar problems for bananas $(r=0.74$; but $\left.\beta_{\mathrm{b}}=0.38\right)$. This growing body of evidence demonstrates the value of the CLUE modelling framework in the field of spatial explicit land use change modelling.

\section{Conclusions}

- Calibration of the CLUE allocation module reveals a strong influence of the parameter that controls the influence of autonomous development at the finest resolution, with improving results when the influence of autonomous development is large.

- The CLUE allocation module is successfully validated over a time period of at least a decade for Costa Rica and Honduras. Validation of omnipresent land uses like natural vegetation and pasture is more successful than the validation of spatially more clustered land uses like bananas and coffee.

- The multi-resolution validation indicates that the increase of predictive power with a lessening spatial resolution is strongly exponential.

- The various studies on the validity of the CLUE modelling framework in Latin America and Asia demonstrate the ability of the model to handle very distinct land use change processes.

\section{Acknowledgements}

This study was financed by NWO/NOP-II. The authors are very grateful to the GIS Department of the Centro Internacional de Agricultura Tropical (CIAT) in Cali, Colombia for their hospitality and willingness to share their data.

\section{References}

Beck, M.B., 1999. Coping with ever larger problems, models, and databases. Water Sci. Technol. 39 (4), 1-11.

Becker, J., 1998. Examples of sustainable development efforts in Costa Rica. Int. J. Sust. Dev. World 5, 172-181.

Becker, A., Bloeschl, G., Hall, A., 1999. Preface to special issue on scale in hydrology. J. Hydrol. 217, 169-170.

Borenstein, D., 1998. Towards a practical method to validate decision support systems. Decis. Support Syst. 23, 227-239.

Brockett, C.D., 1988. Land, Power, and Poverty: Agrarian Transformation and Political Conflict in Central America. Allen \& Unwin, Winchester.

CCE, 1990. Desarrollo rural integrado. Concepto o finalidad? Una experiencia en Costa Rica. Comisión de las Comunidades Europeas, Proyecto CEE NA/82-12. Arafototechnica, Firenze.

Costanza, R., 1989. Model goodness of fit: a multiple resolution procedure. Ecol. Model. 47, 199-215.

De Koning, G.H.J., Veldkamp, A., Fresco, L.O., 1998. Land use in Ecuador: a statistical analysis at different aggregation levels. Agr. Ecosyst. Environ. 70, 231-247.

De Koning, G.H.J., Verburg, P.H., Veldkamp, A., Fresco, L.O., 1999. Multi-scale modelling of land use change dynamics in Ecuador. Agr. Syst. 61, 77-93.

DGEC, 1976. Censo agropecuario 1973. Dirección General de Estadística y Censos, Ministerio de Economía, Industria y Comercio, San José. 
DGEC, 1978. Censo agropecuario 1974. Dirección General de Estadística y Censos, Tegucicalpa.

DGEC, 1987. Censo agropecuario 1984. Dirección General de Estadística y Censos, Ministerio de Economía, Industria y Comercio, San José.

Diaz-Bonilla, E., 1990. Structural adjustment programs and economic stabilization in Central America. EDI Policy Seminar Report No. 23. World Bank, Washington, DC.

Farrow, A., Winograd, M., 2001. Land use modelling at the regional scale: an input to rural sustainability indicators for Central America. Agr. Ecosyst. Environ. 85, 249-268.

Heuvelink, G.B.M., Pebesma, E.J., 1999. Spatial aggregation and soil process modelling. Geoderma 89, 47-65.

Jansen, M.J.W., 1998. Prediction error through modelling concepts and uncertainty from basic data. Nutr. Cycl. Agroecosys. 50, 247-253.

Jansen, H.G.P., Stoorvogel, J.J., 1998. Quantification of aggregation bias in regional agricultural land use models: application to Guácimo county, Costa Rica. Agr. Syst. 58 (3), 417-439.

Jones, J.R., 1988. Colonization in Central America. In: Mansherd, W., Morgan, W. (Eds.), Agricultural Expansion and Pioneer Settlement in the Humid Tropics. United Nations University, Tokyo, pp. 241-265.

Kaimowitz, D., Angelsen, A., 1998. Economic models of tropical deforestation. Center for International Forestry Research (CIFOR), Bogor.

Kok, K., Veldkamp, A., 2000. Multi-scale land use change modelling using the CLUE framework. In: Bouman, B.A.M., Jansen, H.G.P., Schipper, R.A., Hengsdijk, H., Nieuwenhuyse, A. (Eds.), Tools for Land Use Analysis at Different Scales. With Case Studies from Costa Rica. Kluwer Academic Publishers, Dordrecht (Chapter 3).

Kok, K., Veldkamp, A., 2001. Evaluating impact of spatial scales on land use pattern analysis in Central America. Agr. Ecosyst. Environ. 85, 205-221.

Lambin, E.F., 1994. Modelling deforestation processes: a review. Trees Series B, Research Report No. 1. European Commission, EUR 15744 EN, Brussels.

Leemans, R., van den Born, G.J., 1994. Determining the potential distribution of vegetation, crops and agricultural productivity. Water Air Soil Poll. 76, 133-161.

Meentemeyer, V., 1989. Geographical perspectives of space time and scale. Landscape Ecol. 3 (3), 163-173.
Mitchell, P.L., 1997. Misuse of regression for empirical validation of models. Agr. Syst. 54 (3), 313-326.

O'Neill, R.V., 1988. Hierarchy theory and global change. In: Rosswall, T., Woodmansee, R.G., Risser, P.G. (Eds.), Scales and Global Change. Spatial and Temporal Variability in Biospheric and Geospheric Processes, SCOPE 35. Wiley, Chichester, UK, pp. 29-45.

Rudel, T., Roper, J., 1997. The paths of rain forest destruction: cross-national patterns of tropical deforestation. World Dev. 25 (1), 53-65.

Schoorl, J.M., Veldkamp, A., Fresco, L.O., 1997. The conversion of land use and its effects (CLUIE-CR), a regression based model applied to Costa Rica (Pascal version 1.2). Quant. Approaches Syst. Anal. 8, 1-53.

SECPLAN, 1994. Censo agropecuario 1993. Secretaria de planificación, Tegucicalpa.

Sklar, F.H., Costanza, R., 1991. The development of dynamic spatial models for landscape ecology: a review and prognosis. In: Turner, M.G., Gardner, R.H. (Eds.), Quantitative Methods in Landscape Ecology. Ecological Studies, Vol. 82. Springer, Berlin, pp. 239-288.

Stonich, S.C., 1993. The Political Ecology of Poverty and Environmental Destruction in Honduras. Westview Press, Oxford.

Veldkamp, A., Fresco, L.O., 1996a. CLUE: a conceptual model to study the conversion of land use and its effects. Ecol. Model. 85, 253-270.

Veldkamp, A., Fresco, L.O., 1996b. CLUE-CR: an integrated multi-scale model to simulate land use change scenarios in Costa Rica. Ecol. Model. 91, 231-248.

Verburg, P.H., Veldkamp, A., Bouma, J., 1999a. Land use change under conditions of high population pressure: the case of Java. Global Environ. Chang. 9, 303-312.

Verburg, P.H., Veldkamp, A., Fresco, L.O., 1999b. Simulation of changes in the spatial pattern of land use in China. Appl. Geogr. 19, 211-233.

Verburg, P.H., De Koning, G.H.J., Kok, K., Veldkamp, A., Bouma, J., 1999c. A spatial explicit allocation procedure for modelling the pattern of land use change based upon actual land use. Ecol. Model. 116, 45-61.

Wagenet, R.J., 1998. Scale issues in agroecological research chains. Nutr. Cycl. Agroecosys. 50, 23-34.

World Bank, 1998. World Development Indicators, 1997. World Bank CD-ROM. World Bank, Washington, DC. 